\title{
IMPLEMENTASI KURIKULUM 2013 SMK NEGERI KOMPETENSI KEAHLIAN TEKNIK GAMBAR BANGUNAN DI DKI JAKARTA
}

\author{
Hadi Sumantri, ${ }^{1}$ \\ ${ }^{1}$ Alumni Pendidikan Teknik Bangunan FT UNJ,Jakarta, Indonesia. \\ ${ }^{*}$ Corresponding author:
}

Abstract

This research was aimed in order to know the implementation of 2013 Curriculum at Contruction Technical Drawing Competence on the aspects of: (1) Teachers's standard of assessment, (2) The standard of teacher and education staff in this case the competence of teacher and headmaster, (3) The standard of facilities.

This research is comprise to desriptive and quantitative research. The populationo this research was the entire of State Vocational High Schools in DKI Jakarta which have implemented 2013 Curriculum. There were 3 schools as research sample which was gotten by simple random sampling method. The respondents consisted of 3 vice principals of Curriculum, 3 head of contructrion technical drawing competence, and 10 representative students of each teacher in the school. The data collection of this research was gotten by questionnaire, observation, and documentation.

The result of this research showed that the aspects of : (1) the teacher's standard of assessment at the schools whic implemented 2013 Curriculum reached the average $83 \%$ in very good criteria, (2) the standard of teachers and education staff reached the average $83 \%$ in very good criteria for teachers competence, and the average $73 \%$ in good criteria for headmaster competence, (3) the standard of facilities that support the implementation of 2013 Curriculum reached the average $94 \%$ in very good criteria.

Keywords : Implementation, Contruction Techinal Drawing, 2013 Curriculum. 


\section{PENDAHULUAN}

Pelaksanaan Kurikulum 2013 menjadi harapan bagi pemerintah maupun masyarakat Indonesia saat ini. Perubahan kurikulum 2013 yang sudah direncanakan oleh pemerintah diupayakan dalam berbagai tindakan. Adanya pengembangan kurikulum ini diperlukan kesiapan dari berbagai pihak, mulai dari permerintah maupun satuan pendidikan itu sendiri.

Pemerintah melakukan berbagai upaya dalam menunjang pelaksanaan Kurikulum2013. Pemerintah mengadakan pelatihan bagi pendidik dan tenaga kependidikan, pengembangan buku siswa dan buku pedoman guru, pengembangan manajemen kepemimpinan, sistem administrasi, dan pengembangan budaya sekolah serta pendampingan dalam bentuk monitoring dan evaluasi (Dokumen Kurikulum 2013).

Satu hal baru terkait dengan Kurikulum 2013 adalah pendekatan saintifik dalam seluruh proses pembelajaran. Pembelajaran saintifik dalam Kurikulum 2013 dikenal adanya kegiatan mengamati, menanya, menalar, mengasosiasi dan mengkomunikasikan (membangun jejaring sosial). Penilaian autentik yang digunakan dalam kurikulum 2013 terdiri atas penilaian sikap spiritual dan sosial, penilaian keterampilan dan penilaian pengetahuan.

Tugas guru lebih berat dan perlu ketelitian dalam mengenal siswa satu persatu, tidak bisa secara klasikal. Banyak hal yang membuat guru mengalami hambatan yaitu aspek-aspek penilaian sikap itu memiliki beberapa unsur misalnya, nilai kedisiplinan, kerjasama dan sikap menghargai pendapat orang lain, dan lainlain. Selain itu, dalam hal keterampilan juga, guru harus melakukan penilaian observasi dan portofolio. Penilaian dalam aspek pengetahuan dilakukan dengan mengerti, memahami dan mampu mempresentasikan, ada nilai persentasi dan penilain tugastugas.

Sekolah SMK Negeri kompetensi keahlian teknik gambar bangunan di DKI Jakarta telah melaksanakan kurikulum 2013 yang berjumlah 5 sekolah, yaitu SMK Negeri 1, SMK Negeri 26, SMK Negeri 35, SMK Negeri 52, dan SMK Negeri 56. Bagi Sekolah Menengah Kejuruan khususnya Kompetensi Keahlian Teknik Gambar Bangunan, kurikulum pendidikan harus mampu memberikan kualitas lulusan yang bermutu dan kompeten dibidangnya. Sehingga dapat memenuhi tujuan pendidikan SMK yaitu sebagai tenaga kerja tingkat menengah dengan keterampilan khusus sesuai dengan kebutuhan dunia usaha/ industri. Dengan demikian, lulusan SMK memang dipersiapkan untuk mampu memasuki dunia usaha atau dunia industri secara langsung. Tentunnya sesuai, dengan kejuruan yang dipilih oleh masing-masing peserta didik, yang disesusaikan dengan kebutuhan kerja.

Kompetensi keahlian teknik gambar bangunan telah berorientasi pada kesiapan siswa dalam memasuki dunia kerja dibidang kontruksi bangunan, jalan dan jembatan, serta dipesiapakan untuk mampu menjadi wirausaha dibidang kontruksi yang mandiri berbekal kemampuan yang diperoleh di SMK. Kurikulum 2013 yang diterapkan pada kompetensi keahlian teknik gambar bangunan seharusnya relevan dengan kebutuhan tenaga kerja seperti kompetensi juru gambar (drafter), pelaksanaan lapangan, pengawas atau profesi-profesi yang dibutuhkan oleh jasa konsultan. 
Buku yang mengacu pada Kurikulum 2013 terkhusus pada SMK Negeri Kompetensi Keahlian Teknik Gambar Bangunan, dirasa belum maksimal. Buku yang dikeluarkan oleh pemerintah baru beberapa saja, dan belum menyeluruh kepada setiap mata pelajaran yang ada. Kemudian, belum diketahui apakah buku sudah ditangan guru dan siswa ataukah belum dan apakah buku-buku tersebut sudah memenuhi kebutuhan guru maupun siswa.

Peranan layanan pihak sekolah juga menjadi salah satu faktor pendukung pelakasanaan Kurikulum 2013. Sekolah memiliki tugas untuk memberikan pendampingan intensif kepada siswa. Sekolah juga mempunyai tanggung jawab yang besar terhadap usaha mengembangkan kemajuan belajar siswasiswanya dari sarana dan prasarana yang harus memadai untuk mengoptimalkan kompetensi yang dimiliki oleh para siswa. Dimana, sekolah mengusulkan kepada pemerintah untuk menandai fasilitas sarana dan prasarana yang kurang.

Kualitas sarana dan prasarana dapat dilihat dari keberadaan laboratorium dan perpustakaan sekolah. Laboratorium ada tapi terbatas, peralatan dan bahan tidak lengkap, sementara di dalam perpustakaan yang ada hanyalah buku yang digunakan guru dalam proses pembelajaran. Tidak ada pilihan buku yang ditawarkan kepada siswa yang dapat digunakan sebagai sumber belajar.

Selama ini guru telah memiliki gaya mengajar dan pola pikir dalam mendidik yang cenderung tidak berubah, yakni berorientasi kepada konten dan penyelesaian materi. Walaupun standar proses (pembelajaran), standar pendidik dan standar prasarana dan sarana sudah disiapkan, dan pendekatan pembelajaran berpusat pada siswa (student centered apporach) telah lama dikumandangkan, namun suasana pembelajaran yang kondusif, aktif, kreatif, inovatif dan menyenangkan boleh dikatakan belum terinternalisasi oleh pendidikan dalam proses pendidikan.

Pemerintah melalui Peraturan Pemerintah Nomor 19 Tahun 2005 telah menetapkan Standar Nasional Pendidikan (SNP) yang meliputi standar isi, proses, sarana dan prasarana, pendidik dan tenaga kependidikan, kompetensi lulusan , pembiyaan pendidikan, pengelolaan dan penilaian pendidikan . Jika ke -8 standar ini terpenuhi maka mutu pendidikan nasional kita akan meningkat dan dapat bersaing dengan mutu pendidikan negara manapun.

Kurikulum 2013 merupakan kurikulum yang memerlukan pengembangan untuk perbaikan di masa yang akan datang. Selain itu, juga perlu diketahui hambatan atau kendala yang dihadapi oleh sekolah agar dapat diperbaiki dan memperlancar pelaksanaan Kurikulum 2013 pada tahap selanjutnya yang mengacu pada Standar Nasional Pendidikan (SNP). Pelaksanaannya haruslah dipantau dan dievaluasi untuk mengetahui seberapa jauh kurikulum tersebut telah dilaksanakan agar nantinya hal yang menjadi hambatan dalam pelaksanaan kurikulum 2013 ini dapat di atasi dan mengalami kemajuan terutama untuk DKI Jakarta dan daerah lain pada umumnya. Berdasarkan latar belakang tersebut peneliti tertarik untuk melakukan penelitian dengan judul "Implementasi Kurikulum 2013 SMK Negeri Kompetensi Keahlian Teknik Gambar Bangunan di DKI Jakarta". 


\section{METODE PENELITIAN}

Penelitian ini menggunakan metode survei dengan pendekatan kuantitatif. Data kuantitatif merupakan data yang dapat dianalisis secara deskriptif dan berbentuk bilangan. Menurut Winarno Surakhmad (1998:414) mengakatan bahwa penelitian deksriptif adalah penelitian yang bertujuan untuk memperoleh gambaran-gambaran ciriciri variabel.

\section{HASIL PENELITIAN DAN PEMBAHASAN}

Di DKI Jakarta telah ada tujuh SMK Negeri kompetensi gambar bangunan yang telah melaksanakan kurikulum 2013. Tujuh sekolah tersebut merupakan sekolah piloting yang ditunjuk untuk melakasanakan Kurikulum 2013 sejak bulan juli 2013. Dari ketujuh sekolah tersebut hanya tiga sekolah saja yang dijadikan sebagai sampel dalam penelitian ini yaitu SMK Negeri 1 Jakarta, SMK Negeri 26 Jakarta, dan SMK Negeri 35 Jakarta. Responden terdiri dari satu wakil kurikulum, satu kepala kompetensi gambar bangunan, guru kompetensi gambar bangunan dan peserta didik.

Pengambilan data penelitian yang dilakukan pada standar penilaian ini dilakukan untuk melihat gambaran dari penilaian yang dilakukan oleh pendidik meliputi data kuantitatif. Data kuantitatif dalam penelitian standar penilaian oleh pendidik ini, berupa data kuisoner yang diberikan oleh peneliti.

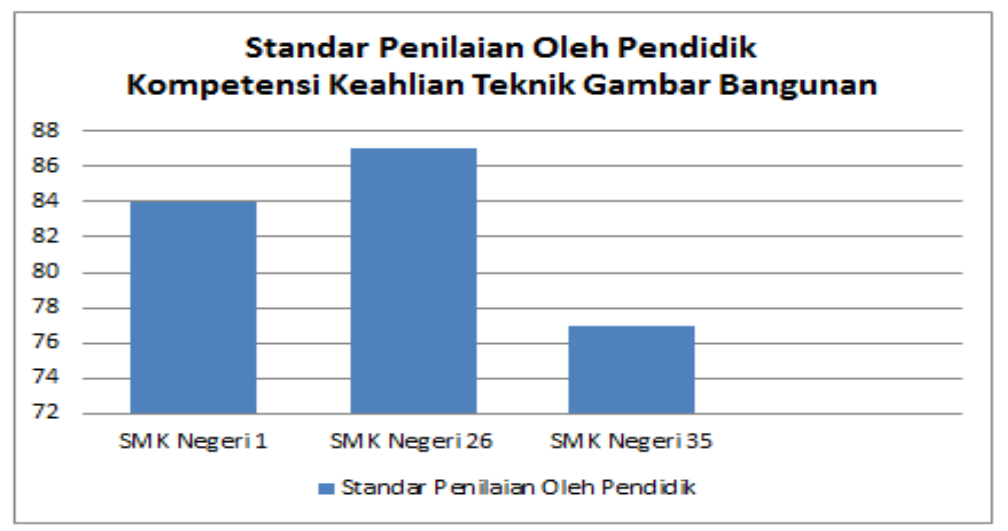

Gambar 1 Diagram Standar Penilaian Oleh Pendidik Kompetensi Keahlian Teknik Gambar Bangunan 
Gambar 1 menunjukkan bahwa rata-rata pelaksanaan dan pelaporan penilaian oleh pendidik kompetensi keahlian teknik gambar bangunan pada sekolah SMK Negeri 1 Jakarta telah melaksanakan sebesar $84 \%$ (Sangat Baik), pada sekolah SMK Negeri 26 Jakarta telah melaksanakan sebesar $87 \%$ (Sangat Baik), dan pada sekolah SMK Negeri 35 Jakarta telah melaksanakan sebesar 77 \% (Baik). Rata-rata keseluruhan dari ketiga sekolah SMK Negeri Kompetensi Keahlian Teknik Gambar Bangunan dalam standar penilaian oleh pendidik telah melaksanakan sebesar $83 \%$ (Sangat Baik).

Pengambilan data penelitian yang dilakukan pada standar penilaian ini dilakukan untuk melihat gambaran dari penilaian yang dilakukan oleh pendidik meliputi data kuantitatif. Data kuantitatif dalam penelitian standar penilaian oleh pendidik ini, berupa data kuisoner yang diberikan oleh peneliti

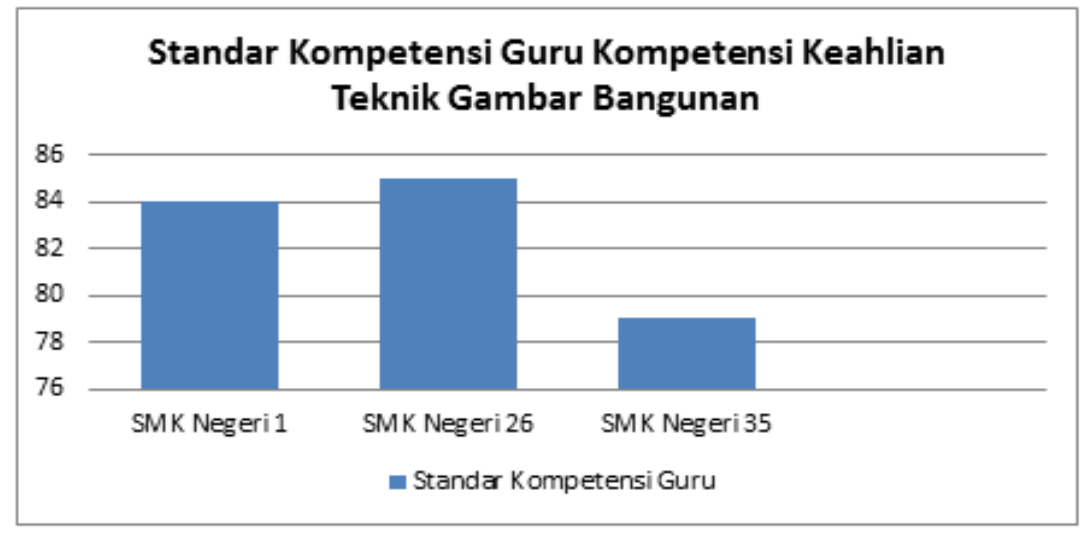

\section{Gambar 2 Diagram Rata - Rata Standar Kompetensi Guru Kompetensi Keahlian Teknik Gambar Bangunan}

Gambar 2 Menunjukkan bahwa rata-rata standar kompetensi guru kompetensi keahlian teknik gambar bangunan pada sekolah SMK Negeri 1 Jakarta mendapat nilai sebesar $84 \%$ (Sangat Baik), pada sekolah SMK Negeri 26 Jakarta mendapat nilai sebesar 85 \% (Sangat Baik), dan pada sekolah SMK Negeri 35 Jakarta mendapat nilai sebesar $79 \%$ (Baik). Rata-rata keseluruhan dari ketiga sekolah SMK Negeri Kompetensi Keahlian Teknik Gambar
Bangunan pada standar kompetensi guru mendapat nilai sebesar 83 \% (Sangat Baik).

Pengambilan data penelitian yang dilakukan pada standar penilaian ini dilakukan untuk melihat gambaran dari penilaian yang dilakukan oleh pendidik meliputi data kuantitatif. Data kuantitatif dalam penelitian standar kepala sekolah, berupa data kuisoner yang diberikan oleh peneliti. 


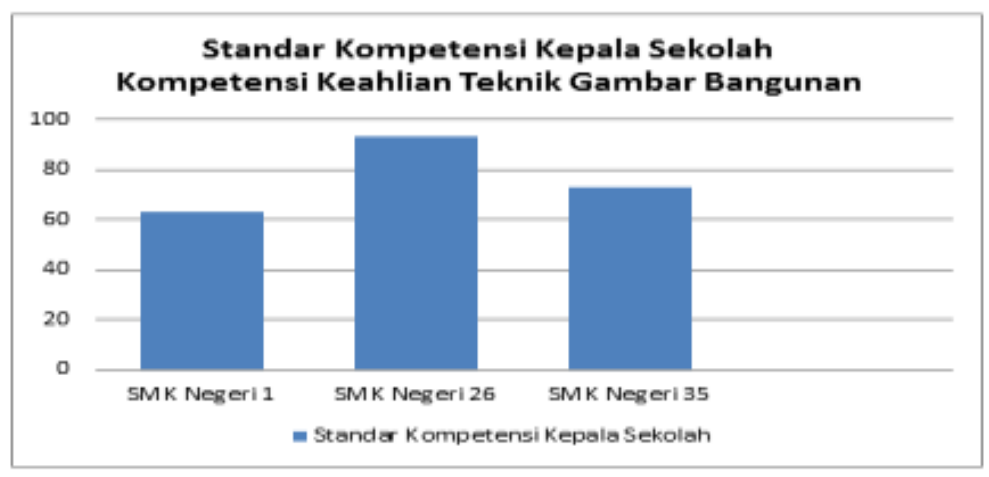

\section{Gambar 3 Diagram Standar Kompetensi Kepala Sekolah di Nilai dari Responden Kompetensi Keahlian Teknik Gambar Bangunan}

Gambar 3 menunjukkan bahwa ratarata standar kompetensi kepala sekolah dinilai oleh responden keahlian teknik gambar bangunan pada sekolah SMK Negeri 1 Jakarta mendapat nilai sebesar 63 $\%$ (Baik), pada sekolah SMK Negeri 26 Jakarta mendapat nilai sebesar $93 \%$ (Sangat Baik), dan pada sekolah SMK Negeri 35 Jakarta mendapat nilai sebesar 73 $\%$ (Baik). Rata-rata keseluruhan dari ketiga sekolah SMK Negeri Kompetensi Keahlian Teknik Gambar Bangunan pada standar kompetensi kepala seekolah mendapat nilai sebesar $76 \%$ (Baik).

Sekolah Menengah Kejuruan Negeri Jakarta telah mengacu kepada Standar Nasiona sarana dan prasarana kelengkapan yang dimiliki oleh sekolah tersebut antara lain: 1) Gedung sekolah pondasi permanen dan lokasinya sangat mudah dijangkau, aman dan nyaman, gedung dilengkapi sistem keamanan, dilengkapi fasilitas instalasi listrik dengan daya minimum 1300 watt; 2) Kelengkapan sarana dan prasarana telah dilengkapi dengan adanya ruang kelas, ruang perpustakan, laboratorium, ruang pimpinan (ruang kepala sekolah), ruang guru, ruang tata usaha, tempat beribadah, ruang konseling, jamban (toilet/kamar mandi), gudang, tempat berolahraga, dan ruang Praktik Kerja/bengkel kerja. Walaupun dari semua item di atas masih ada sekolah yang masih belum memilikinya antara lain laboratorium gambar teknik bangunan, buku siswa, dan buku panduan kurikkulum 2013.

Keterlaksanaan penunjang sarana dan prasarana di dalam Kurikulum 2013 di SMK Negeri 1 Jakarta tercapai sebesar $92 \%$ ( Sangat Baik ), pada SMK Negeri 26 Jakarta tercapai sebesar $100 \%$, dan pada SMK Negeri 35 Jakarta tercapai sebesar 91 $\%$. Rata-rata keterlakasanaan penunjang kurikulum 2013 di dalam standar sarana dan prasarana di ketiga sekolah kompetensi keahlian teknik bangunan SMK Negeri di DKI Jakarta sebesar $94 \%$ dalam kriteria sangat baik.

\section{KESIMPULAN}

1. Penilaian kompetensi pengetahuan yaitu membuat tes, remedial dan pengayaan, serta penilaian kompetensi keterampilan dalam hal ini penilaian praktik, proyek dan portofolio. Pendidik telah melaksanakan penilaian pendidikan di dalam Kurikulum 2013 dengan telah melaksanakan rata-rata dari ketiga sekolah SMK Negeri di DKI Jakarta sebesar $83 \%$ dalam kriteria Sangat Baik.

2. Kemampuan kompetensi guru di dalam kurikulum 2013 yaitu kompetensi pedagogik, kepribadian, sosial dan 
profesional. Rata-rata keseluruhan dari ketiga sekolah SMK Negeri Kompetensi Keahlian Teknik Gambar Bangunan di DKI Jakarta pada standar kompetensi guru mendapat nilai sebesar $83 \%$ (Sangat Baik).

3. Kemampuan kompetensi kepala sekolah di dalam kurikulum 2013 yaitu kompetensi edukasi, manajerial, administor, supervisi, leader, inovator dan motivator. berdasarkan penilaian responden keahlian teknik gambar bangunan pada sekolah SMK Negeri 1 Jakarta mendapat nilai sebesar $63 \%$ (Baik), pada sekolah SMK Negeri 26 Jakarta mendapat nilai sebesar $93 \%$ (Sangat Baik), dan pada sekolah SMK Negeri 35 Jakarta mendapat nilai $\begin{array}{llll}\text { sebesar } 73 \% & \text { (Baik). Rata-rata }\end{array}$ keseluruhan dari ketiga sekolah SMK Negeri Kompetensi Keahlian Teknik Gambar Bangunan pada standar kompetensi kepala seekolah mendapat nilai sebesar $76 \%$ (Baik).

4. Keterlaksanaan penunjang sarana dan prasarana di dalam Kurikulum 2013 di SMK Negeri 1 Jakarta tercapai sebesar $92 \%$ ( Sangat Baik ), pada SMK Negeri 26 Jakarta tercapai sebesar $100 \%$, dan pada SMK Negeri 35 Jakarta tercapai sebesar $91 \%$. Rata-rata keterlakasanaan penunjang kurikulum 2013 di dalam standar sarana dan prasarana di ketiga sekolah kompetensi keahlian teknik bangunan SMK Negeri di DKI Jakarta sebesar $94 \%$ dalam kriteria sangat baik.

\section{DAFTAR PUSTAKA}

Arikunto, Suharsimi. (2005). Manajemen Penelitian Yogyakarta: Rineka Cipta. .
Arikunto, Suharsimi. (2010). Prosedur Penelitian : Suatu Pendekatan Praktik. Yogyakarta: Rineka Cipta. .

Kementerian Pendidikan dan Kebudayaan. (2012). Bahan Uji Publik Kurikulum 2013. Jakarta: Kementerian Pendidikan dan Kebudayaan.

Mulyasa, E. (2013). Pengembangan dan Implementasi Kurikulum 2013. Bandung: PT. Remaja Rosdakarya.

Peraturan Menteri Pendidikan dan Kebudayaan.(2013). peraturan menteri pendidikan dan kebudayaan nomor 66 tahun 2013 tentang standar penilaian pendidikan. Jakarta : Kementerian Pendidikan dan Kebudayaan.

Peraturan Menteri Pendidikan dan Kebudayaan.(2013). peraturan menteri pendidikan dan kebudayaan nomor 70 tahun 2013 tentang kerangka dasar dan struktur kurikulum sekolah menengah kejuruan/madrasah aliyah kejuruan. Jakarta : Kementerian Pendidikan dan Kebudayaan.

Peraturan Menteri Pendidikan Nasional dan Kebudayaan No. 54 Tahun 2013 tentang Implementasi Kurikulum.

Peraturan Menteri Pendidikan Nasional dan Kebudayaan No. 66 Tahun 2013 tentang Standar Proses Penilaian.

Peraturan Menteri Pendidikan Nasional dan Kebudayaan No. 81A Tahun 2013 tentang Standar Kompetensi Lulusan Pendidikan Dasar dan Menengah. 
Peraturan Pemerintah No. 19 Tahun 2005

Pemerintah No. 19 Tahun 2005

tentang Standar Nasional Pendidikan.

tentang Standar Nasional Pendidikan.

Peratuaran Menteri Pendidikan Nasional

Republik Indonesia Nomor 40

Tahun 2008 tentang standar sarana

dan prasarana

Peraturan Pemerintah No. 32 Tahun 2013 tentang Perubahan Atas Peraturan 